\title{
Las peripecias de Dios en la historia de América: Providencialismo y probabilismo
}

\author{
Alan Martín Pisconte Quispe* \\ Instituto de Investigaciones del Pensamiento Latinoamericano (IIPLA)
}

\begin{abstract}
La relación con la tradición no nos procura un punto firme sobre el cual apoyarnos, si no que nos empuja a una especie de remontarnos ad infinitum en el cual se hace fluido el presunto carácter definitivo y contundente de los horizontes históricos en los cuales nos encontramos.

Gianni Vattimo
\end{abstract}

$\mathrm{U}$ no de los mayores problemas que afronta América, específicamente América Latina y con más precisión, el Perú, es la carencia y — hasta ahoradificultad de plantearse una adecuada definición de sí mismo. En consecuencia, nuestra manera de aproximarnos al mundo y su re-creación discursiva presentan profundos vacíos. Este ensayo pretende mostrar hipótesis plausibles acerca del porqué de estas dificultades. Una de tales dificultades acecha ya desde que planteamos el problema, pues al decir «nuestra manera» ¿quién se esconde bajo el pronombre posesivo «nosotros»? Como sugería Heidegger, el quien del ser-en -el mundo (la intersubjetividad) se haya en un estado abierto, es decir, ese quien ha construido históricamente un mundo hospitalario se vuelve inhóspito una vez que se presentan dificultades en su periferia y es necesario ya no salvar el «núcleo duro» del paradigma cultural, sino establecer sus límites.

Graduado de nuestra Facultad. Es Bachiller y Licenciado en Filosofía. Es investigador del IIPLA. El presente trabajo fue premiado en los Juegos Florales 2001 en Ensayo. 
Partamos de un momento crítico de la historia humana: el descubrimiento de América. ${ }^{1}$ y 2 Desde el ángulo que se lo prescriba — eurocéntrico o desde América - ese acontecimiento parece haber decidido la construcción —aún vigente-del imaginario colectivo americano ${ }^{3}$, especialmente el meridional.

Vayamos por partes. Desde el ángulo europeo, el providencialismo se constituyó en la ideología aglutinante de los deseos de un Orbe Universal cuyas esperanzas se cifraban en la búsqueda por alcanzar el reino celestial. ${ }^{4}$ Los estados nacionales que comenzaban a surgir en la baja Edad Media $^{5}$ ponían el énfasis en una identidad nacional basada en términos divinos, como la recuperación de los lugares sagrados en manos de los infieles y la propagación del evangelio a todo el orbe. Esta búsqueda providencialista de unidad, tuvo una variante clásica en el renacimiento italiano, cuya consecución neoplatónica y hermética buscó conciliar todos los saberes en una originaria «materia católica» o también llamada «prisca sapientia» (saber antiguo). ${ }^{6}$

El providencialismo tuvo históricamente su origen teórico con san Agustín dentro de un período histórico de búsquedas espirituales en el orbe europeo, puesto que la episteme grecorromana se hallaba en crisis. Si el providencialismo sugiere que la mano de Dios se halla en cada acto del mundo, de allí se puede desprender que el resultado lógico de esta búsqueda espiritual es la escolástica,

1 El término "Descubrimiento de América» lo usamos por una cuestión de convención, sin embargo es necesario aclarar que el enunciado revela un matiz eurocéntrico.

2 «Pero aún a mediados del siglo XVII, las asombrosas posibilidades atisbadas ya al comienzo del siglo XVI apenas habían comenzado a comprenderse. A pesar de los problemas originados por el creciente conocimiento de América, no se había organizado todavía ningún ataque sobre la validez histórica y cronológica de la versión bíblica de la creación del hombre [...]. La filosofía política y social de Europa permaneció todavía intacta [...]. Las posibilidades del relativismo como arma para combatir las concepciones religiosas, políticas y sociales, casi no habían sido comprendidas aun». J.H. ELLIOTT, El Viejo y el Nuevo Mundo (1492-1650). Madrid, Alianza Editorial, 1972, p. 42.

3 Obviamente, el encuentro de América y Europa tuvo también consecuencias en la construcción del imaginario colectivo europeo; sin embargo tal problema no será discutido en el presente ensayo.

4 Antonello Gerbi, La disputa del Nuevo Mundo. Historia de una polémica (1750-1900). México, Fondo de Cultura Económica, 1982, pp. 161 y ss.

5 Cuya consecución teórica y punto de arranque fue Guillermo de Ockham.

6 Antonio González Blanco y Simonettz Scandelari, «El Hermetismo en la España de los siglos XV- XVIII en el Renacimiento Italiano». Actas del II Congreso Nacional de Italianistas. Murcia, 1984. Edición de la Universidad de Salamanca, 1986, pp. 175 y ss. 
entendida ésta como la articulación y sistematización de todos los saberes humanos en relación con el Orden Sobrenatural, pues se requiere tamaña hazaña intelectual para poder hacer plausible — al menos para los hombres de aquella época - que cada acción humana y natural estén regidas bajo un Orden considerado divino, es decir, suprahumano, cuyas reglas - bajo tamaño fundamento- eran inevitables paradigmas sagrados a seguir. ${ }^{7}$

Con la novedad americana, se intentó encarar el nuevo orden del mundo con dos posturas nuevas: la total globalizante y la total racionalizante ${ }^{8}$ con lo que se terminó por resquebrajar el punto de vista anterior.

Dos hechos históricos fueron claves para entender la primera postura: la lucha providencial española contra el Islam y el florecimiento de la cultura humanística en la ciudades-estado italianas. El primero fue el motivo «vital» que empujó la expansión española, tuvo como máximo exponente a Colón, quien insuflado de providencialismo, creyó que el paraíso se hallaba en América y que la marcha humana se dirigía a Occidente. El segundo aportó los anteojos conceptuales con los que se encaró la novedad americana, como Pedro Mártir de Anglería, quien se dio cuenta de que las diferencias sustanciales halladas en América debilitaban el paradigma escolástico ${ }^{9}$. Pero en ambos casos surge un intento reflejo de acomodar un nuevo continente a las estructuras mentales tradicionales, aún en Pedro Mártir (de manera negativa: «América no es Europa»).

Éste instintivo intento de asimilación era comprensible, no habiendo formas alternativas de encarar la cuestión. Los hispanos y su élite intelectual no tuvieron más que apelar a lo dado, y fue la escolástica tomista a la que se recurrió para llevar a cabo un intento de rearticulación del orden providencial que se estaba resquebrajando. Pero las tesis tomistas no quedarían incólumes ante la prueba

7 No es necesario relatar el proceso lento de desmitificación de tal búsqueda providencial, pero sí es necesario resaltar que tal lentitud sólo posibilitaba mantener el providencialismo como sentido común en Europa.

8 La primera, tradicional y escolástica - específicamente de segunda escolástica-; y la segunda, moderna e instrumental que será motivo de disertación al final del presente ensayo.

9 Julio Gerardo Martínez M., «Providencialismo, Sagradas Escrituras y Religiosidad en el Descubrimiento de las Indias en el Reino de Granada y el Nuevo Mundo». V Congreso Internacional de Historia de América. Mayo de 1992, vol. 3, ed. de la Diputación Provincial de Granada, 1994, pp. 101 y 102. 
americana en ciernes, sobre todo las tesis geográficas, o, dicho en jerga escolástica: el «Orden Natural». Las tesis antropológicas existentes se pondrán en cuestión ante la aparición abrupta en el escenario mundial, de una miríada impresionante de nuevas formas culturales, que llevarán por ejemplo, al escepticismo cultural y gnoseológico francés.

En cambio, las elites hispánicas (como Vitoria o Acosta) intentarán rearticular, bajo los supuestos antropológicos aristotélico-tomistas, la categoría de «bárbaro» y sus variantes. En el orden sobrenatural y teológico, encajar el Nuevo Mundo dentro de la mitología cristiana llevará al optimismo cósmico de un Bruno, es decir, a la pluralidad de mundos. Entre los escrituristas hispanos más bien se intentó salvar el dogma católico a toda costa. ${ }^{10}$ Se erige así la denominada «segunda escolática», que — al igual que el humanismo italiano — rebuscará y revisará exhaustivamente el saber greco-latino. Además, basados en el dogma escriturístico y en santo Tomás, buscará rearticular las novedades que se presentan en todos los frentes teóricos.

Se produce así una espantosa búsqueda histórico-bibliográfica de las fuentes tradicionales con el fin de hallar pistas de la nueva realidad en los sabios antiguos, pues América desafiaba siglos de conocimiento.

El descubrimiento y conquista del Orbe Indiano fue presidida tanto por la curiosidad humanista y aristotélica («todos los hombres por naturaleza desean saber») como por el designio providencial, alimentado por la «virtu» renacentista de los conquistadores. Este providencialismo ya no es estrictamente de corte teórico-lógico como lo fue en la Edad Media, sino utilitario-histórico, inaugurándose, de manera proteica, los signos de la modernidad. Por ejemplo, el padre Acosta - que hizo un gran esfuerzo por encajar en tópicos conceptuales aristotélicos-tomista el Nuevo Mundo-, se preguntaba si no era que Dios hubiera previsto que el oro y la plata incalculable de las Indias fueran destinados a los españoles como premio y compensación por las pérdidas del Viejo Orbe en manos de la herejía protestante. De igual modo argumentaba Hernán Cortés, declarando a Carlos V como un emperador que no tenía problemas en América (como los tenía en Europa) para erigirse Señor absoluto de sus tierras y gobierno. América entonces era culminación histórica y premio pecuniario.

$10 \quad$ J.H. ElLiotT, op. cit., pp. 43 y 44. 
Ergo, curiosidad y rapiña fueron los modos de encarar el reto del Nuevo Mundo. ${ }^{11}$ Lo primero representado sobre todo por los cronistas y los humanistas españoles, y lo segundo por la soldadera encomendera, luego por la burocracia colonial y luego ¿quizá por las diferentes formas de Estado que hemos tenido hasta la actualidad?

Ambas, curiosidad y rapiña, sacramentados a través de supuestos gnoseológicos y morales aristotélico-tomistas - bajo un modo conservador-caracterizaron la manera de afrontar el mundo y la vida, tanto en el período de «estabilización colonial» ${ }^{12}$ posterior a la conquista, como el proceso de derrumbe que sufrió dicha estabilización, ¿o será que en realidad no hubo tal derrumbe, sino que se trata — si se habla de nuestra «independencia»— de la conservación del status quo?

La curiosidad produjo las monstruosas crónicas que pulularon a lo largo de la colonia, desde las primeras de corte humanista, hasta las del siglo XVII de corte apologético — regalista o religioso ${ }^{13}$ — con envoltorio hermético y neoplatónico, que, aparte de privilegiar la cantidad de información, también privilegió el énfasis en un estilo frondosísimo y ostentoso, originándose el consabido «barroco». Lujos que se pudieron costear por el oro y la plata indianos, al menos en arquitectura. ${ }^{14}$

Esta erudita curiosidad rara vez llevó al replanteamiento de los supuestos aristotélico-tomistas, a lo más a darse cuenta de la peligrosidad exegética en la que la élite intelectual colonial se debatía al afrontar la articulación de las novedades americanas. En otros casos llevó abiertamente a la apología, pues todos los intentos se destinaron a defender teóricamente las bases aristotélico-tomista asumidas, y la búsqueda de armonía en los órdenes natural, moral y providencial. Este aliento conservador infesta todas las obras teóricas de la élite cultural colonial ya que bajo esos marcos tomistas se subsumió, tanto la hermética y el neoplatonismo, como el posterior ingreso de la ciencia moderna. A tales teorías

J.H. Elliott, op. cit., pp. 45 y 46.

12 Denominación de Carlos García-Bedoya en La literatura peruana en el Período de Estabilización Colonial. Lima, Fondo Editorial de la UNMSM, 2000, p. 12.

13 Antonio de León Pinelo o el Padre Calancha para citar algunos ejemplos.

14 J.H. ElLiot, op. cit., p. 84. 
se les dio un uso meramente instrumental, muy lejos del pragmatismo de corte anglosajón secular, pues sólo resultaban útiles mientras no pusieran en cuestión el dogma tomista y cristiano y sustentaran el orden providencial.

La rapiña, legitimada por el aliento providencial que subyace a la conquista, tendrá su consecución en el exclusivismo que se arroga la España imperial sobre el Nuevo Orbe, dando apertura al monopolio comercial. Claro que el camino a la estructuración de un Orden Providencial no iba a ser fácil de ningún modo, las múltiples incógnitas que, como fermentos para el asombro, se abrían en todos los frentes, pronto llevó al debilitamiento de la tradición, y a la desesperada búsqueda de acomodar las novedades americanas a tal orden.

Sin embargo, ello se produjo sacrificando grandes áreas del saber tradicional en los ámbitos natural y moral; sacrificio cuya explicación consciente es tematizada en la metrópoli por la denominada «segunda escolástica». Dichos esbozos articuladores, tuvieron su seguidilla teórica sobre todo con los relatos y crónicas, en las exploraciones marítimas geográficas y en la puesta en marcha de la ordenación y sistematización de las «Leyes de Indias».

Entonces, si el aliento espiritual que presidió la conquista y demás etapas de la «estabilización colonial» fue la integración en un Todo Providencial, el modo o instrumental para conseguirlo fue lo que se conocería ya en el siglo XVIII como «probabilismo», que en sus primeras etapas de aparición en el XVI y el XVII tuvo metas políticas menos virulentas que las que tuvo en el XVIII. Al principio este probabilismo produjo variantes menos radicales como el «equiprobabilismo», de corte suareciano y el «probabiliorismo», encausadas dentro del método casuístico, ${ }^{15} \mathrm{el}$ cual se usó tanto en el ámbito moral como en el natural, y también en el de exégesis bíblica (providencial).

Recuérdese pues, que tal intento de integración buscaba en este caso, no la separación (y consiguiente especialización teórica y metódica, como en el caso de las sociedades modernas) en compartimentos estancos de tales ámbitos, sino su continuidad y jerarquización, tal como había sido en términos generales,

15 Martín Grabmann, Historia de la Teología Católica, desde fines de la patrística hasta nuestros dias. Madrid, Espasa-Calpe, 1946, pp. 181 y ss.; p. 196. 
antes del descubrimiento del Nuevo Orbe; por lo que es comprensible el uso de tal instrumental probabilista para lograrlo.

Lo común a esas variantes probabilistas es el énfasis en los hechos históricos a los cuales la ley debe aplicarse. Un mundo estamental detenido en espacio y tiempo como el medieval, se mostraba ahora circunscrito y limitado a un período de tiempo donde las leyes — que regían su mundo jerárquico - perdían ahora su capacidad legislativa omniabarcante, ante el surgimiento de circunstancias históricas que no estaban previstas en la ley, tornándola meramente probable y ya no rigurosa como antaño. Con el método casuístico —usado por teólogos, canonistas y juristas - se buscó conjurar el azar, pues con tal método se procede a limitar el alcance de la ley solo a ciertos casos, y a determinar nuevas normas para la circunstancia no prevista. Se constituye una especie de escepticismo que - a diferencia de la duda metódica cartesiana - preserva y deja incólume la ley pero la limita, de tal modo que la teoría, (representada por la ley) y la práctica (histórica) de las normas constantemente entran en contradicción.

En el orden natural, todas las crónicas empiezan manifestando «lo probable» que se han vuelto las tesis aristotélicas sobre la zona tórrida; en el orden moral, todas manifiestan la dificultad de dar cuenta de la variedad cultural de «los bárbaros», por lo que se vuelven «probables» los métodos de prédica a través de medios pacíficos en el caso de los religiosos, o se vuelven probables los modos y normas legislativas dadas en una época histórica, ${ }^{16}$ y se buscan vías para disponer de inéditas normas que abracen las nuevas formas de vida abiertas. León Pinelo ${ }^{17}$ comienza volviendo «probables» aquellas tesis tradicionales donde surjan discrepancias con la palabra bíblica (que asume el papel de «ley»), permitiendo adjudicar el lugar del Paraíso a América como una tesis probable.

De esta manera, con el probabilismo se logra sustentar el Orden Sobrenatural, el privilegio de posesión de estas tierras a la misión providencial de España, además de resolver el problema del origen y estatus de los indios y de la Naturaleza Americana en los ámbitos moral y natural respectivamente.

\footnotetext{
16 Las «Nuevas Leyes» que propició Las Casas, por ejemplo.

17 LEÓn DE PINELo abarca el ámbito providencial en la exégesis bíblica que realiza con su obra Paraíso en el Nuevo Mundo, obra a la cual nos referimos en este párrafo.
} 
La jerarquía del cosmos, con órdenes y lugares «absolutos» y naturales —además de apuntalarse tal jerarquía con base en los elementos cualitativos hipocráticos en el mundo sublunar- sigue teniendo vigencia «formal» en el orden natural. Bajo esta armazón se adscriben, de manera instrumental y acrítica, las novedades teóricas científicas en la navegación, la astronomía y las ciencias en general. En el orden moral se sigue manteniendo la unidad jerárquica de la ley natural y civil, con la ley sobrenatural; y es dentro de la ley civil que se establecen los cambios circunstanciales. Con tal jerarquía se explica el caso del pacto social de tipo orgánico. ${ }^{18}$ Tal pacto establece que el poder tiene su origen en Dios, el cual lo delega al pueblo, y el pueblo por su parte lo destina al Rey, el cual una vez ungido por el pueblo, tiene carácter divino. Puesto que Dios no le ha conferido el poder directamente, el rey debe velar por el Bien Común del «organismo político» o de los grupos sociales basados en estamentos o castas, con lo que se evita que el rey se erija en tirano y el gobierno en una monarquía absoluta. Pero mientras el rey vele por el bien común, el pueblo debe someterse a la autoridad divina del rey, puesto que Dios lo ha elegido, aun cuando haya sido por vía indirecta (a través del pueblo).

Debido a esto se ha interpretado la situación política en las colonias en el siglo XVIII: o como una democracia moderna (si el énfasis con relación al poder se coloca en el pueblo) o como despotismo ilustrado (si el énfasis se coloca en el rey). Pero dichas interpretaciones permanecen enclavadas en una explicación ahistórica. Pues tal situación política sólo adquiere su verdadero espesor epistémico si las adscribimos en este casuismo probabilista, el cual no toca en lo más mínimo el armazón teórico tomista, pues subyace la idea de un «corpus misticum» en relación con la política, el cual se guía por la ley providencial divina. De la misma manera, tampoco se cuestiona radicalmente la cosmogonía subyacente al relato bíblico, sino que se la toma como presupuesto formal en el que se intenta encajar las novedades geográficas y cosmológicas - que aparecieron junto con los viajes intercontinentales. Tal es el caso de autores como Gregorio García y su Origen de los Indios o como Antonio de León de Pinelo, quienes asumen la periodización bíblica adecuándola a las circunstancias nuevas sin hacer una crítica de dicha periodización.

18 Como en SuÁrez y Bellarmino, y no basado en individuos libres. 
Por otro lado, en el siglo XVII, los recursos teóricos del hermetismo y neoplatonismo permiten explicar los cambio sustanciales entre las jerarquías en que está ordenado el cosmos, y permite introducir la noción de milagros y apariciones sobrenaturales (con lo que se crea un ambiente parecido al medioevo). En el siglo XVIII, la irrupción de las novedades racionalistas limpia el cauce de este injerto hermético, pero en ningún caso se procede a una crítica a fondo del armazón tomista corregido y aumentado por la «segunda escolástica» y puesto en marcha gracias al método probabilista.

De manera que providencialismo y probabilismo - con todas sus consecuencias - insuflan nuestras búsquedas teóricas. Además parecen tener injerencia en la aparición de nuestros sentimientos nacionalistas de corte religioso. Los criollos — basados en Solórzano Pereira— sugieren la importancia del suelo y naturaleza indianos como sostén del orden providencial de la monarquía española. Así, el oro y la plata de Indias mantienen la guerra contra los herejes europeos. Y sus quejas se sustentan en que, a pesar de la importancia del mundo indiano para tal búsqueda y lucha religiosa, el gobierno central desdeña a los naturales americanos. ${ }^{19}$ Por otro lado, Túpac Amaru II se basó en las tesis integracionistas del Inca Garcilaso, el cual sostenía que dicha integración entre las élites españolas y cuzqueñas, se basaba en la superioridad providencial de las primeras. ${ }^{20}$ En conclusión creer que «el paraíso es americano» es sinónimo de que «Dios está con nosotros»o «Dios es peruano». Nuestra nación, y quizá las naciones americanas, tienen raíces profundamente religiosas alimentando su identidad nacional.

Los patriotas criollos utilizaron el instrumental teórico del probabilismo para debilitar el poder español en las Indias acusándolo de «tirano» y de ir contra el Orden Natural, pero ¿cuál es ése orden? Ya lo esbozamos anteriormente: el creado en el siglo XVI con la «segunda escolástica». Los tiranos borbónicos eran una circunstancia histórica deleznable que no había cumplido con vigilar y propiciar el Bien Común.

19 David Brading, Orbe Indiano. De la monarquía católica a la república criolla. 14921867. México, Fondo de Cultura Económica, 1998, pp. 239 y ss.

$20 \quad$ Ibid., pp. 283 y ss. 
En consecuencia, lo plausible es que — como sugiere Stoetzer ${ }^{21}$ — nuestra supuesta independencia ilustrada, sea más bien una reacción conservadora atenta a defender el status quo, el cual se erigió con mucho esfuerzo tras el descubrimiento de América, a través de siglos de «estabilización colonial». Es de sentido común que el cambio de dinastía, de la Habsburgo a la Borbónica fue, sino el inicio, sí el catalizador para arramblar con lo establecido y fomentar una paulatina secularización. Secularización que en la metrópoli se impidió tras las luchas contra Napoleón y su expulsión; y en las colonias, con las luchas independentistas (?). Al parecer, ambos movimientos fueron de corte conservador: en si se «conservó» el modo providencial de establecerse en el mundo y la vida.

La misión providencial española fue puesta en práctica y llevada a cabo a través del ímpetu y empuje de todo un pueblo que se movilizó tras una búsqueda utópica de mejoría en un Nuevo Mundo. Allí se cumpliría sus ansias de un paraíso terrenal. Así, tras la virtu española subyace toda una retórica formal providencial y tradicional (aristotélico-tomista) que les permitió afianzarse como un imperio que — siendo de índole puramente continental — podía desdeñar el reciente descubrimiento ${ }^{22}$ y que por tanto podía arrogarse todos los esquemas teóricos tradicionales, además de todos los valores morales vigentes, necesarios a un imperio que se logró bajo el empuje de las virtudes clásicas de valentía y arrojo. Virtudes necesarias para un reino formado básicamente por tropas terrestres y cuya eficacia dependió de la unidad teórica (providencialismo) y moral («virtu»).

Pero esto ya no es el caso del imperio de Felipe II, cuyos gastos de guerra no podían ser costeados por el oro y la plata de sus territorios de Austria, sino que cada vez más dependía de las riquezas que provenían de ultramar, encontrándose de improviso —e históricamente - el gran rey del Escorial, ante un nuevo paisaje cultural. Él se hallaba dueño de un imperio básicamente marítimo, su grandeza se debía ya no a las fuerzas morales que empujaron las tropas de su padre, sino a las riquezas ingentes que costeaban su lucha providencial.

\footnotetext{
21 O. Carlos Stoetzer, Las raíces escolásticas de la emancipación de la América española. Madrid, Centro de Estudios Constitucionales, 1982. Véase la Introducción.

22 Como sugiere J.H. ElLiott.
} 
Permanecer en el poder ya no dependía del sostenimiento de los valores y teorías heredadas de la tradición, que sólo podían responder a un imperio terrestre; el descubrimiento de América lo ponía ante la situación de afrontarlo ya no con arrojo e ímpetu, sino con miras mundiales y estrategias colonizadoras, lo ponía en el trance de tener que variar una sociedad de corte místico-religiosa y estamental por una basada más en el trabajo y la productividad, por el impulso de la navegación y el comercio cuyas riquezas reviertan en la misma metrópoli, basada en la manufactura y no en la ostentación y el adorno barroco.

Pero todo ello equivalía a trastocar desde sus cimientos aquella tradición que le habría empujado a la conquista terrestre tanto en Europa como en las colonias. Pero lo que se hizo en la fase de estabilización fue todo lo contrario. ${ }^{23}$

Los reinados posteriores a Felipe II, los de Felipe III y IV, tienen la unanimidad de los historiadores en cuanto a reinados de decadencia en todo el amplio sentido del término, tanto en la metrópoli como posiblemente en las colonias. Las luchas estamentales se hicieron insoportables y evidentes: entre el burocratismo del imperio y las órdenes mendicantes, las pugnas entre estas órdenes y la jerarquía eclesiástica. En este incierto panorama la mano trabajadora se encontró desdeñada desde lo «alto» de estas ocupaciones de hombres-bien. Las «historias» de la Iglesia y de las órdenes mendicantes, las hagiografías y las crónicas, son muestras palpables de estas luchas, que también se producían - aunque con motivaciones que ligeramente diferían - en las colonias. Las historias de la Iglesia y de las órdenes mendicantes, a primera vista, defendían la prioridad y antigüedad (la prestancia) de tales órdenes, pero una mirada entre líneas nos revela que su objetivo era seguir gozando de los privilegios pecuniarios que habían gozado con el descubrimiento y la conquista.

Las crónicas — sobre todo las auspiciadas por el «círculo toledano»— trataban de resaltar la labor del imperio español en la conquista y evangelización; en tanto que las hagiografías tenían como fermento los primeros síntomas de un protonacionalismo encargado de elevar a todos los oídos la consigna de que en las colonias o en la metrópoli Dios favorecía con sus bendiciones a tales tierras. Recuérdese cómo para Vitoria, el derecho de conquista sólo se basaba en la

23 J.H. Elliotr, op. cit., pp. 110. 
prédica y no en la fuerza, y que por tanto, un síntoma de que los indios habían aceptado la palabra era los anuncios milagrosos y sobrenaturales; pero Vitoria era escéptico sobre que tales anuncios se estuvieran dando en la conquista (por las noticias propaladas por Las Casas y la «leyenda negra») Pero en caso de existir tales señales, entonces, los indios no se podían rebelar dado que el espacio americano ya estaba consagrado a Dios. Si lo hacían, podían ser considerados herejes, es decir, rebeldes a la palabra divina, y por ende, castigados. ${ }^{24}$

La etapa de estabilización colonial se encargaría de mostrar que ya se vivía un ambiente religioso en las Indias, con sus milagros y sus biografías de santos indianos, además del típico culto mariano del XVII, tan fomentado por Suárez y otros jesuitas como el padre Nieremberg en la metrópoli, y por Antonio de León de Pinelo, o el padre Calancha en América.

En síntesis, los desafíos que abría el descubrimiento para la irrupción providencial hispana, era el de encontrarse ante un vasto imperio comercial de índole mundial y marítimo; desafío al que Felipe II volvió a responder — como su padre Carlos V-de una manera tradicional y conservadora: impidiendo el libre albedrío y restringiendo la lectura en lengua vulgar de la Biblia - tan necesaria para el proceso de individuación en otras partes de globo- - y reiniciando con fuerza las luchas de religión — tendientes a propiciar el reinado divino en la tierracon el consiguiente despilfarro de las riquezas metálicas americanas y desgaste de la población hispana en las guerras, sin dirigir la fuerza a la producción.

Esto tuvo como resultado, no sólo el aumento de los precios al no haber una sólida estructura productiva - ¿cómo podía haberla en un país con un sentido fuertemente aristocrático, alimentado desde sus dos venas intelectuales, la religiosa y la nobiliaria? - si no también la exacerbación del casuismo, y por tanto, la expansión universitaria de los estudios jurídicos en detrimento de los estu-

24 «[Según Vitoria] sólo después de haberles predicado adecuada y eficazmente, pueden ser responsables ante Dios si no creen [...] De aquí la dificultad: ¿qué motivos de credibilidad exige Vitoria? [...] Exige argumentos probables y racionales y con una vida digna [...] y cuidadosa en conformidad con la ley natural [...] Y no está seguro de que la fe cristiana haya sido de tal manera propuesta y anunciada a los bárbaros que estén obligados a creerla [...] Porque no ve milagros, ni señales ni religiosos ejemplos de vida [...] sino más bien todo lo contrario». Paulino Castañeda Delgado, Los memoriales del padre Silva sobre Predicación Pacífica y Repartimientos. Madrid, Consejo Superior de Investigaciones Científicas, Instituto «Gonzalo Fernández de Oviedo», 1963, pp. 9 y 10. 
dios de pura reflexión como las «artes» y los «estudios bíblicos» que facilitaron las armas teóricas para la conquista, pero que quizá con su revaloración de la escolástica y de la elitización de los estudios humanísticos — acaparados por religiosos y juristas - crearon su propia muerte.

Así, llegó un momento en que la «aplicación» casuística jurídica de los presupuestos escolásticos (o de segunda escolástica), al encontrarse con sus propios límites - las novedades americanas y el naciente capitalismo que no pudieron asumir - se estancó, y al haber secado de raíz los estudios de índole reflexiva, como la teología (relegada a las órdenes monásticas) y las «artes», además de los estudios bíblicos —además de verse rodeada por una abundante burocracia (nobles, soldados y juristas) — no pudo por sí misma y desde sí misma, florecer en una etapa de autoconciencia. ${ }^{25}$

En el silo XVII, el vacío de estudios no jurídicos fue llenado por los jesuitas, cuyo humanismo «debilitado», es decir, tendiente a supeditar el saber racional al moral y teológico, favoreció una tendencia conservadora y hasta servil en el peor de los casos, donde dicho saber no era un «fin en sí mismo», sino una propedéutica para la moral y la religión, propiciando así generaciones sometidas al imperio, el cual era considerado (con los Habsburgo), la encarnación de lo religioso y de las normas sociales ${ }^{26}$ y 27 .

Esta reacción conservadora del Imperio no podía darse en peor momento. Los nacientes estados imperiales (Inglaterra, Países Bajos, Francia e Italia) ya comenzaban a disputar a España la supremacía mercantil en todas sus fronteras coloniales. Mas, de lo que se preocupaban las élites intelectuales en el siglo XVII era de hacer notar a tales naciones - a través de las crónicas oficiales y de las órdenes monásticas — su legitimidad «providencial» para legalizar su lucha en Europa.

25 Historia de la Acción Educadora de la Iglesia en España, Edades Antigua, Media y Moderna. Obra dirigida por Bernabé Bartolomé Martínez. Madrid, B.A.C., 1995, pp. 470 y ss.

$26 \quad$ Ibid., pp. 474 y ss.

27 De este modo los jesuitas se aseguraron un lugar en la jerarquía social, donde las pugnas con otras órdenes se debían al cada vez más evidente hecho de que la acumulación de riquezas y tierras en manos clericales no fomentaban la productividad y desviaba los recursos a la ostentación (léase más Iglesias y más colegios); es por eso que resulta imprescindible que se mostrase como «la Orden» que había logrado mejores frutos en la evangelización, surgiendo así las historias de las órdenes con un claro fin apologético. 
Pues en Europa, a pesar de todo, la «virtu» española, de corte terrestre, aun les era favorable. Pero Holanda comenzó a ganar por mar. En el plano ideológico, tal lucha se notaba en el uso indiscriminado por parte de los Países Bajos, de propaganda antihispánica, usando los escritos del padre Las Casas, y en la metrópoli y en las colonias comenzó a prohibirse la circulación de tales obras.

La inflación - debido a que el oro y la plata no permanecían en España pues tenían que comprar por altos precios toda la tecnología que no podían producir-, las dificultades tecnológicas de extracción de metales en las colonias - donde la mano de obra indígena por desgaste o por rebelión impedía la explotación uniforme - , las pérdidas de colonias de ultramar, la incursión de piratas, la guerra de los Treinta años — que significó la pérdida de Portugal y de la hegemonía mundial - no tuvieron una respuesta inmediata de tipo reflexiva, sino un arrinconarse en un fervor religioso que sobrenadaba en una corrupción en todos los frentes de la tambaleante jerarquía, además se propició los estudios asiduos del estoicismo - especialmente de Séneca - que ya tenía cierta tradición en España, pero que se fomentará sobremanera con el carteo de la élite intelectual del siglo XVII con el gran erudito Justo Lipsio, experto en senequismo. ${ }^{28}$

Así pues, la literatura por la época está dirigida a «adornar» y «ocultar» mediante una avalancha moral-religiosa, un problema que estaba más allá de esos presupuestos tradicionales.

Se apeló a las hagiografías, al catecismo para indios, a la educación jesuita, a la devoción mariana, al estoicismo, a todo lo tradicional para conjurar un problema que iba más allá de esa mezcla de humanismo y teología escolástica

28 «Pero cuando lo hizo Azpilcueta [una observación sobre la riqueza de las Indias] la situación económica estaba empezando a cambiar. Los precios de los productos castellanos estaban aumentando más rápidamente que los de los otros países y la balanza comercial de Castilla con otros países de Europa [...] era más desfavorable, ya que importaba más productos de los que exportaba y tenía que cubrir el déficit con la plata americana. Este cambio gradual se veía acompañado por una creciente desilusión con respecto a las riquezas de América, que se manifestaba en las continuas quejas de las Cortes de Castilla sobre la subida de los precios y en la creciente profusión de comentarios sobre los moralmente perniciosos efectos de esa riqueza. El mayor logro de Castilla era precisamente la fuente de su ruina. 'Novus Orbis victus vos vicit' -'Vencido por vosotros, os ha vencido a su vez el Nuevo Mundo'- escribió Justus Lipsius a un amigo español en 1603». J. H. Elliott, op. cit., p. 82. 
favorecido por la escuela de Salamanca, pues estas corrientes ponían el énfasis en la dimensión religiosa y moral — que luchaban por no separar — cuando los problemas se abrían por el lado más terrenal de lo económico y político e inauguraban la modernidad y el protocapitalismo.

Por lo tanto, se requería una autorreflexión sobre cómo se había afrontado el reto de América; el cual — como se ha resaltado — se afrontó en base al providencialismo y al probabilismo: el primero de tendencia irreflexiva, que requería sobre todo fuerza, vitalidad y dogmatismo; el segundo ahorró debates sobre cuestiones de fundamentos, preocupándose más por la índole «aplicativa» de los presupuestos de la segunda escolástica, aplicación llevada a cabo por la burocracia (léase juristas). Esa vertiente «práctica» era — como se vio — alimentada por la vena utilitaria que tenía el providencialismo hispano, el cual resaltaba la idea de compensación religiosa ante las guerras de religión en Europa.

El probabilismo sirvió como herramienta para sustentar el poder español sobre las colonias, debilitando las tesis teocráticas del papado en la Edad Media y dando libertad de acción al emperador. Por otro lado, permitió la configuración de América según el saber tradicional, pues hizo «probables» venerables tesis geográficas y cosmológicas, como las de Aristóteles (la zona tórrida) Las tesis probabilistas permitieron especular acerca del origen de los indios, que, empezando con Las Casas y Acosta, tuvo su consecución en León Pinelo, el cual, al colocar el paraíso en el Nuevo Mundo, hizo probables - y no de ley- las tesis que colocan tal origen en el Viejo Orbe. El probabilismo, tímidamente, hacía flexibles los lazos con la tradición pero no fomentaba el desembarazo de ella.

Así, el impulso providencial, apoyado por el instrumental probabilista, fomentó el surgimiento del imperio hispano.

Luego, al hacerse notorio que el poder marítimo del imperio providencial de Felipe II se debía en gran parte a las riquezas indianas, se fomentó la idea de Nación Criolla entre los habitantes de las colonias. Dicha idea de nación se alimentaba en esa vertiente providencialista. Así, el padre Calancha y León Pinelo - y sus lejanos antecedentes, Las Casas y más tímidamente, Acostacreían que las tierras americanas eran favorecidas por la providencia. Por otro lado, en el siglo XVIII, el debate sobre el probabilismo tomó un cariz ya no de 
escuela como en el siglo XVII, ${ }^{29}$ sino político-moral, pues tal instrumental sirvió para favorecer el separatismo de las colonias. Y los argumentos usados por los separatistas consistían en propiciar la rebelión contra el monarca, debido a que éste descuidaba el bien común de los habitantes. Es decir, descuidaba el debido orden, dado que el rey había sido elegido por el pueblo, y éste era el representante de los designios de Dios.

Pero ¿cambiaron acaso los usos tradicionales?, ¿acaso se dejó atrás la idea de Providencia y probabilismo?, ¿no son éstos totalmente de índole conservador y autoritario? Obviamente este providencialismo ya no tiene el carácter cerrado que tuvo en la Edad media, pues ya no se sustenta en una fuerte estructura dogmática-teórica, dado que el probabilismo sirvió para construir una más dúctil; pero esta ductilidad no debe inducirnos a error pues era de carácter práctico y no de reflexión, aunque pudo haberla tenido al principio, en el siglo XVI con la segunda escolástica, pero ella misma se creó sus mecanismos de ahogamiento intelectual al favorecer estudios humanísticos de élite, además se apropio de los instrumentos teóricos de la escolástica, ya no con metas teoréticas, como con los grandes maestros de la Edad Media, sino con un fuerte sabor histórico-erudito.

La gran excepción podría ser Suárez, pero es conocido que fue más aprovechado por los países nórdicos, especialmente por Alemania, ${ }^{30}$ que por los hispanos, quienes sólo echaron guante a sus escritos «prácticos» de probabilismo.

Esta praxis era tan ciega que llegado el momento de reflexión, al no bastar ya su propuesta tradicional, se arrinconaron en la plegaria, en la bravuconería o en el estoicismo.

Los atisbos de modernidad fueron de índole conservador. Ya en el Siglo de las Luces en Europa, un «ilustrado» como Antonio Ulloa, sugiere que se puede aceptar la tesis de Copérnico porque «no están en contra de las Sagradas Escrituras». ${ }^{31}$ Quizá sigue aquí al jesuita Bellarmino, el cual aceptaba las tesis de

29 «Nadie puede negar el alto valor doctrinal de los teólogos españoles del siglo XVI [...] En contraste, las polémicas teológicas del siglo XVII son fundamentalmente discusiones de escuela [...]», en «Historia de la Acción Educadora...», op. cit., pp. 373 y 374.

30 F. Canals Vidal, Historia de la Filosofia Medieval. Barcelona, Herder, 1980, pp. 335 y ss.

31 D. Jorge Juan y Antonio UlloA, Observaciones Astronómicas y Físicas en los Reinos del Perú. Madrid, Impreso por Juan de Zúñiga, 1748. Véase el prólogo. 
Copérnico «instrumentalmente»y no con sus disolventes posibilidades ontológicas.

En general, los jesuitas tratan de preservar los estudios modernos de su virulencia en el orden social, moral y religioso, conminándolos a su forma tradicional. Un ejemplo de ello serían: el padre Rher, S.J., que estudió el fuego, o el erudito Cosme Bueno, que estudió el aire y el agua, y ya en el siglo XIX, el sabio José Gregorio Paredes, ${ }^{32}$ la tierra. Así, seguían preservando la estructura cualitativa clásica, a pesar de considerarse a todos ellos «ilustrados». Dentro de este formalismo, subsumen las novedades científicas modernas, dándoles un carácter meramente erudito e instrumental, mas impidieron una crítica de presupuestos ontológicos.

Posteriormente, ya en el siglo XIX, al perder confianza en su híbrido intelectual providencial-probabilístico, los hispanos comenzaron a mirar «hacia fuera» - como habían mirado antes para defender sus privilegios imperiales - pero dicho mirar o era de corte autoapologético o era sumiso. La mayor de las veces fue un pendular hacia cada polo. Cuando el ingreso de la cultura francesa amenazaba arramblar con la tradición, los españoles la detenían con las consabidas frases del «ser español» de carácter vital, que fue el motor que alimentó sus grandezas providenciales.

Por tanto, el carácter arisco e independiente español, es sólo el impulso idealista hacia una totalidad terrestre, hacia un imperio perdido que se anhela recuperar. Terminan así añorando el «siglo de oro» o se hace alarde sobre sus «virtudes», evitando un debate a fondo de su desdeñada identidad.

Pero, por otro lado, en la práctica, tal actitud añorante se canalizó en una sutil imitación de lo foráneo a través de una enfermiza erudición, un «estar al día» sobre aquello que no es producción intelectual propia para estar a la altura de lo último en Europa, deteniéndose esta »hambre imitativa» cuando lo asimilado acríticamente colisiona con los fundamentos últimos, que son su «sentir» providencial y su aplicación «práctica» erudita, además de su conservadurismo

32 «[... siguiendo las huellas [de Cosme Bueno] en sus disertaciones del fuego, el agua y el aire, daremos una ojeada sobre la tierra [...]». José Gregorio PARedes, Almanaque Peruano y Guía de Forasteros, Lima, 1821. Véase la introducción. 
probabilístico, modo metódico que les sirvió (¿y sirve?) para asimilar — sin ser destruidos - las novedades europeas. Sólo cuando se roza dicha posibilidad de destrucción, al tocar los fundamentos nombrados, surge el «vitalismo español», que destruye todo lo anterior, que creen en su totalidad de origen foráneo, y empiezan de cero, impidiendo una autorreflexión sobre su tradición.

José Luis Abellán cree que la tradición española es de carácter mítico-religiosa (lo que aquí nombramos como útil) y no dialógica. Esta última característica la atribuye al carácter religioso de índole católica, la cual constituye una constante de la tradición de pensamiento hispánico. ${ }^{33}$ No negamos ello, pero creemos además que esa falta de diálogo autorreflexivo con la tradición, se debe también al carácter tradicional de su saber, que es práctico en el peor sentido, además de jerarquizante — como se vio al nombrar su reapropiación en la escolástica — y de reflexión tendiente al conservadurismo (probabilismo).

Tendrá que esperarse hasta la Generación del 98 con Unamuno y demás, para empezar un tímido ahondar en sus problemas de fundamento, pero aun así se evidencia cómo está dirigido por un afán apologético. ${ }^{34}$

El lado a investigar, al menos someramente, es cómo estas opciones de fundamento, cómo el «compromiso ontológico» adquirido por la cultura «oficial» criolla heredó tales características, providencialismo, probabilismo, además de la erudición meramente asimilativa que se sigue de ello.

Son conocidas las tesis de Stoetzer sobre las raíces escolásticas de la Independencia Americana, el instrumental probabilístico sirvió aquí para debilitar el regalismo de la metrópoli que, bebiendo de fuentes francesas, adoptaba el despotismo ilustrado, subsumiendo de ley a la Iglesia y a las colonias bajo su poder y cambiando con ello la relativa independencia que encomenderos y religiosos habían salvaguardado por medio de las tesis de laxitud del poder temporal y papal para propiciar su mutua armonía e interrelación, lo cual no se logró pero

33 José Luis Abellán, Historia crítica del pensamiento español. Madrid, Espasa-Calpe, 1979, tomo I, pp. 128 y ss.

34 Léase por ejemplo su texto sobre El Quijote que, sin lugar a dudas, es el emblema de esta tendencia providencial, erudita, elitista y probabilista del imaginario colectivo hispano. Pero éste es un aspecto que nos interesa menos. 
que era lo que mantenía el modo de relacionarse socialmente en el siglo XVII. Así pues, el probabilismo permitió la reacción conservadora cuando la metrópoli decidió romper las reglas de juego de tensiones estamentales, y canalizó todo proyecto de vida a través de la intervención directa del Estado.

Lo que esgrimían los criollos era la idea de que ellos eran «hijos del país» (o «amantes del país») y esa nación tenía ya un buen tiempo de autodenominarse un lugar escogido por la providencia. Por lo que, si el paraíso era americano, la bondad de sus gentes era por «naturaleza». Así devolvían apologéticamente, los desdenes que la metrópoli les encaraba con el fin de gozar del poder en las colonias, haciendo notar la calidad igual o superior de los nativos criollos en relación con los gachupines. Estaba en juego la idea de providencia, además del determinismo climático, la cual, dependiendo del énfasis en tal providencia, favorecía o contradecía las pretensiones de alcurnia de los criollos. Si Dios era americano, entonces «por naturaleza» los nativos eran mejores que los hombres de la metrópoli. Pero por otro lado, para mantener la subordinación indígena, los criollos los tildaban de bárbaros. Luego, un determinismo climático favorable no alcanzaba a los antiguos nativos, debido a que el providencialismo era sobre todo criollo.

Pero al librarse del dominio político de la metrópoli, los nativos americanos se encontraron ante la interrogante de qué hacer ahora que ya no subsiste la verticalidad social que mal que bien sustentaba el orden desde la metrópoli. La lucha caudillista no se hizo esperar. La élite intelectual seguía un ritmo autoapologético defendiendo la «hispanicidad»o, por el contrario, la autodenigración, que en la práctica —al igual que la metrópoli- la lleva a tomar acríticamente los productos culturales que no emergían de entre ellos.

Así, la «naturaleza americana», que primero permitió el autobombo cultural, ahora producía su debacle: «por naturaleza», los americanos eran incapaces de asumir los retos de una sociedad moderna; y, por consiguiente, este lloriqueo intelectual impedía asumir autoconciencia sobre la apuesta providencial subyacente.

Entonces, el «copismo», a través de una prudencia «probabilista», sumió el papel de instrumento intelectual con el cual se captaron en bloque acríticamente 
y de manera práctica — praxis de tradición providencial— los aportes modernos. Tales aportes modernos, o de cualquier filosofía, descontextualizados, son tomados como leyes que se deben asumir y no criticar; y cuando estos elementos injertados tienden a disolver lo establecido — estamentos en pugna — se pasa a tomar otros aportes foráneos descontextualizados, previo rechazo de la retórica anterior.

La facilidad con que en nuestra tradición de pensamiento se asume y se desafora retóricas foráneas se explica por este modo probabilista que las asume como ley hasta que dejan de ser útiles a los intereses que esgrimen tal modo probabilista; y ello sucede no sólo entre las lecturas de la élite intelectual, sino que también es usado por la élite política.

Entonces la ley adquiere carácter coercitivo mientras sirve, y los cambios de reglamento se producen cuando el que las esgrimió caduca y otro toma el poder, con la consecuente secuela de caos político del que no hablaremos in extenso por ser ya abrumadoramente conocido.

Luego, probabilismo y providencialismo propician en nuestro actuar social inestabilidad y retóricas autoritarias, produciéndose ese raro inmovilismo que ya notaba Alberto Flores Galindo en su «Ciudad Sumergida», con relación al Perú. Quizá en nuestro país esto es más notorio, pues hasta el siglo XVIII y XIX, fue el centro conservador por excelencia, pues aquí el cultivo de los tópicos providenciales y el método probabilista fue exhaustivo. Así, tras nuestras tensiones sociales, mediatizadas por las retóricas intelectuales y políticas, se hallan conjuntos sociales y culturales en un ensordecedor y mutuo ninguneo.

Desprendo de lo dicho hasta aquí que estos modos providencial y probabilístico, impiden afrontar — por su propia índole práctico-vital antirreflexivados problemas que hemos tocado someramente y que se muestran difíciles de encarar: el problema del indio y el de la modernidad.

Son problemas que las élites culturales americanas - y creo también hispana- han encontrado desde inicios de su amalgamación cultural en la época de la colonia y más acá en la historia. Problemas que se han cristalizado al parecer en la dicotomía que ha sido notada por nuestros historiadores y pensadores: el Perú oficial y el Perú profundo. 
El primer lado de la dicotomía se ha alimentado, para sustentar su poder, en vertientes teóricas foráneas, y al descontextualizarlas, les ha permitido mantener un aura de sacralidad, importante para conferir al poder estatal un barniz providencial.

El modo probabilista es el instrumental — que, por lo escrito antes, es de origen colonial — que ha permitido desprender dichas teorías de sus «modos de vida» de origen, y ante tal descontextualización, anularon su poder de disolvencia adecuándolo a los esquemas autoritarios (providencial) y permitiendo su aceptación masiva erudita y meramente retórica.

Para Marx, un pueblo existe en tanto toma conciencia de sus presupuestos ontológicos, pero al impedirse esa reflexión, nuestra consecuente falta de existencia ha llevado al mutuo autoninguneo de los estamentos en pugna, que se ha vuelto «sentido común» en nuestro trato diario intersubjetivo e internacional, pues el providencialismo ha permitido que sobreviva un trato social basado en castas y jerarquías que, aunque móviles en la práctica, en el discurso se asumen estáticas y propician la exclusión mutua, a pesar del reciente «laberinto de la choledad» que, como Nuggent y Matos Mar resaltan, ha producido una invasión cultural de la pluralidad trasandina a la capital, centro del criollismo cultural.

Pero ello no ha producido un mestizaje armonizador, sino una violencia urbana sui géneris. ${ }^{35}$ Así, este parloteo cultural entre sordos, también se refleja en la poco sólida estructura de nación lograda hasta hoy, la cual requiere de un eje común. Esto produce una pendulación social, desde un extremo chauvinista excluyente y fervoroso, a una irritación con nosotros mismos en tanto proyecto común; pendulación que demuestra la nulidad de tal proyecto.

En filosofía, las retóricas, reflejando esa pendulación, han pasado de un extremo racionalista a otro espiritualista de corte irracional. Esta observación, anotada por el maestro Salazar Bondy, a nuestro parecer refleja cómo la vertiente autoritaria providencial asume las tesis racionalistas (segunda escolástica,

35 En los 80's Sendero Luminoso y los grupos paramilitares, y en los 90's la «cultura chicha» surgida en los conos, el gregarismo sin-sentido juvenil que ha propiciado la delincuencia pandillera alrededor de motivos poco sólidos como la diversión y el fútbol de masas. 
positivismo, marxismo, liberalismo) como axiomas indiscutibles. Todo lo contrario a lo que propiciaron en sus contextos de origen, pues esas filosofías tenían un alto poder de crítica de lo establecido, mientras acá, por su aparente poder de omnicom-prensión, son tomadas como palabra divina, y se revisten de un aura religiosa de corte excluyente. ${ }^{36}$ Pero al arraigarse artificialmente en un contexto totalmente nuevo y no originar tales filosofías una autocrítica - dado que son asumidas como ley, y de manera rigorística ${ }^{37}$ — se pasa al extremo contrario de asumirlas cada vez más laxamente, en un esfuerzo por hacerlas compatibles con la multiplicidad de intereses subyacentes.

Pero aun así, se salva el «núcleo duro» de nuestros presupuestos, y en lugar de pasarse a la ya necesaria autorreflexión, simplemente se cambia de retórica, de «pomada salvadora».

Las propuestas de vertiente irracionalista - por denominarlas de alguna manera- son usadas para disolver el frágil artefacto teórico creado anteriormente, y surgen los caudillos aislados, que en lugar de afrontar el problema, vociferan su independencia hispánica, vomitando frases de aparente vanguardia y de recién tomada libertad, sin darse cuenta de la trampa pendular en que se encuentran, por su igualmente sospechosa falta de miras históricas.

El lado racional con retóricas y praxis autoritarias, va disolviéndose y se llega a un extremo de atomización de estamentos que se autoanulan y no dialogan entre sí. Entonces aparecen las voces del sentido común: «necesitamos orden, un orden fuerte, 'alguien' que ordene esto, 'mano dura'». Y cada 'mano fuerte' que surge, viene con su propia propuesta retórica ${ }^{38}$. De esta manera, la «reconstrucción nacional», la «moralización ahora-sí del país», las retóricas morales y hasta religiosas, reemplazan la reflexión urgente y se vuelve a negar el pasado. «Ya nunca más», solemos decir; pero es en el escarbar el pasado donde se origina la reflexión y ese escarbar es ninguneado por las retóricas nuevas que se enfrentan al pasado asumiéndolo en bloque — como hacen con las retóricas

36 Véase por ejemplo, en nuestra comunidad sanmarquina cómo el neopositivismo y el marxismo adquirieron, entre sus correligionarios, carácter de secta.

37 En términos probabilistas: tuciorísticamente.

38 Sea neopositivismo, marxismo o neoliberalismo, que son reconocidas como tales en la teoría - o mejor dicho, en la retórica- pero no así en la práctica, donde todas se disuelven en la imposición. 
foráneas - y la consideran la «época oscura»o «mala». Luego se asumen como el «verdadero cambio»y, como todo lo que se asume desde su inicio como verdadero, excluyen otras posibilidades, despejando el área para una aplicación sin restricciones.

Todo lo dicho nos indica que tales maneras de afrontar la praxis cotidiana nos alejan del debate filosófico que debería asumir el problema de la autorreflexión y el de cómo entender el denominado «proyecto occidental» que se ha venido aceptando acríticamente en la mayoría de los casos. Ya vimos cómo ante el mismo reto, Felipe II decidió volver sobre sus fueros de manera ciegamente práctica. Me parece que se mantiene la misma postura ante el «proyecto moderno» pues se le ha tomado en bloque, o se le ha admitido servilmente.

Creo además que nos ha cegado la similitud de formas del proyecto providencial religioso hispano con el proyecto providencial anglosajón, cada vez de índole más secular hasta llegar a denominarse simplemente «progreso»o «tecnología»o «ciencia».

Este proyecto providencial que denominé como «total-racionalizante», moderna y antitradicional por su proyecto de «desencantamiento» — puntualizado por Weber - ha reemplazado la dimensión sagrada por una de praxis racional e instrumental, con miras totalizantes - si no en base en metarrelatos, sí con base en una praxis tecnológica - y que, desde que se inauguró y tomó conciencia de sí, desterró todo edificio conceptual y todo saber antiguo por prestarse a la mera especulación y no atenerse a los «hechos» sensibles y posibles de cuantificar.

Así, un saber jerárquico y teórico que ligaba entre sí estamentos, fue reemplazado por un saber que se atenía a lo estrictamente individual, a la experiencia fenoménica, a la representación - que siempre lo es de un individuo. Pero la idea de «progreso» que subyacía a tales proyectos providenciales, y ambos de carácter práctico (compensación divina), los ligaba e hizo que el proyecto hispánico, sea admirado en primera instancia por haber reasumido y englobado para tal proyecto, todas las fuentes tradicionales, morales, teóricas y epistémicas existentes; pero a la vez, produjo escepticismo al toparse con una otredad casi invencible: América. 
Tal escepticismo en el mundo europeo no hispánico, potenció la búsqueda de mecanismos no-tradicionales para la expansión providencial, con éxito dentro de lo que indican sus normas políticas basadas en el consenso individual: enriquecimiento material y manipulación de la naturaleza.

Tal éxito propició que los hispanos no apelen a la reflexión para su propia articulación cultural, pues al perseguir las mismas metas de enriquecimiento providencial y al ver el éxito foráneo, su tendencia fue llegar a imitarlos y adecuarse a los modos de vida modernos.

Pero ahora que el proyecto moderno muestra sus límites ¿seguiremos en el mismo afán imitativo? Esta pregunta se hace necesaria al observar que en el caso del proyecto providencial español-criollo, tal imitación tenía un cierto tipo de lógica al perseguir metas afines con el proyecto providencial moderno, pero discrepaban en el énfasis religioso (hispano) y en el método (probabilismo y erudición), como he pretendido mostrar. La rapiña se legitimaba providencialmente en el caso hispano, se mostró basada en el «ímpetus», en la vitalidad española, en tanto que en el caso anglosajón se mostró fríamente instrumental.

Vayamos ahora al otro lado de la dicotomía. El nombrado «Perú profundo» igualmente fue visto primeramente en bloque y denominado peyorativamente «bárbaro», aunque hubo matices como el de Alonso de Ercilla que veía a los «profundos peruanos» como «nobles germanos», o el Renacimiento italiano y francés (Pedro Mártir, Montaigne y luego Rousseau) que los percibió como los habitantes de la mítica «Edad de oro» o del «paraíso perdido», en claro afán utópico.

Pero esos intentos trataban de subsumir como un todo la «novedad americana» abierta de improviso ante ellos. Así, se apeló a todo el arsenal existente: religión cristiana, historia clásica, saber greco-latino y especulación escolástica. Los intentos de comprensión provenientes del providencialismo anglosajón tampoco fueron auspiciosos: ninguneo histórico hegeliano, primitivismo kantiano, objeto de prosperidad material para los pionner americanos, y, últimamente dicotomías semióticas de enfoque racionalista francés (estructuralismo antropo-lógico de Lévi-Strauss). 
Así, creemos que se ha sepultado infaliblemente una voz que, no obstante, ha sobrevivido y mantiene vigente sus modos de vida, praxis sociales y sentir propios, sin olvidarnos que de todas maneras se han producido mezclas culturales en todos los aspectos de la vida, desde la música hasta la literatura.

El método estructuralista usado por los científicos sociales en el Perú, como Rostworowski, Pierre Duviols, Luis Millones, Juan Ossio, etc., parece haber llegado a sus límites. Pero gracias a su intervención, la pluralidad cultural del Perú profundo ha sido mostrada tanto en su historia como en sus estructuras sociales y en su cosmovisión. Mas, cabe sospechar que sólo han cogido los entes y no el ser de tales entes, es decir, al parecer sólo ven lo que sus previas apuestas gnoseológicas les han permitido ver. Sospecho que lo mismo se puede extender a los otros modos teóricos de haber encarado el problema en la historia latinoamericana y más precisamente, peruana.

Ya Acosta había señalado la singularidad del lenguaje usado entre los indios, que además de tener una variedad riquísima, parecía ser de índole pictográfico. Por otro lado, dicho lenguaje parece tendiente a presentar «sentimientos», «emociones» al parecer de tendencia colectivos y cósmicos más no individuales.

Quizá se deba a ello las dificultades de encarar esta sociedad llamada consensualmente «mundo andino» pues el fervor religioso hispano, si no era de índole jerárquico-excluyente - de toda otra forma de vida, relegada al cajón de sastre de «bárbaros»- era totalmente arisco-individual. Todo lo cual llevaba una visión diametralmente opuesta con respecto al «mundo andino», que en lugar de ser excluyente, buscó denodadamente asimilar, no sólo en la práctica sino también en su discurso, los modos culturales que de improviso la encaraban.

Por otro lado, los científicos sociales, quiérase o no, participan del modo de ver «objetivo» inaugurado por el pensamiento occidental ${ }^{39}$ lo cual les impide enfocar el carácter «participativo», «comunal»y «emotivo»—diríamos «lúdico»— de los lazos sociales andinos. La dificultad de encararse con «Voz propia» — si vale el término — ha originado que se tomen posturas imitativas -

39 Aun cuando este occidentalismo pueda tener otras vertientes, el objetivismo es predominante. 
al menos en el nivel del discurso- como en el caso de Felipe Huamán Poma de Ayala o el Inca Garcilaso de la Vega. Recientemente Vallejo, Arguedas y Gamaliel Churata se han preocupado explícitamente por articular un castellano que muestre de una manera propia el sentir cósmico y lúdico de la gente del ande. Particularmente estos últimos, por alguna razón, decidieron el camino literario, el lenguaje abierto y siempre cósmico de la poesía y de la narración en prosa. ¿Será que por allí, por el sendero artístico, se pueda mostrar y desplegar sobremanera, «la voluntad de poder» que se articula en las creaciones culturales del «mundo andino»?

Todo lo dicho hasta ahora, y especialmente lo último, linda en el margen especulativo que posibilita el Ensayo como género discursivo. Así pues, ¿no será necesario tematizar quizá con nuevos métodos y nueva voz, sobre un imaginario cultural tan variado como el americano y peruano? La tematización de este imaginario resultaría muy interesante pues se ha caracterizado por haber forjado una sólida tradición y por ser de índole literaria, como señalan Vargas Llosa y Octavio Paz.

Quizá está en ciernes una filosofía lúdica, creativa, como la forjada en Argentina por Borges, Cortázar y Sábato, para sólo nombrar algunos; en ellos, sin perder lo lúdico y creativo se ha obtenido una mirada unificante. En el Perú, nuestras obras literarias (tuvieran o no mayores alcances como lo han tenido en la práctica) se han visto sesgadas en sus alcances por sus mismos creadores, autodenominándose «nacionales», «cosmopolitas», «regionalistas», etc. Aun así es la vía literaria con su probabilismo la que ha posibilitado con mayor éxito que la reflexión filosófica, hacer laxas las corrientes foráneas en literatura, y producir mezclas propias con mejores y más sólidas raíces en nuestro sentir cultural plural.

Así pues, sea cual fuere el camino que decidamos andar, es innegable lo necesario de la autorreflexión sobre nosotros mismos y el encuentro o la construcción del lenguaje que hable de y por nosotros mismos. La vieja consigna socrática del «conócete a ti mismo» creemos se ha cumplido en literatura, mas es necesario añadirle el «atrévete a usar tu propia razón» kantiano.

Los retos y las dificultades son grandes y en un primer paso hemos tratado de mostrar tales dificultades en su riqueza y complejidad; sin embargo debemos 
estar en la capacidad de asumirlas para no continuar en la vegetación reflexiva y en un movimiento impulsado por la imitación, la imposición o la destrucción.

Sin ánimos de pesimismo, creo que vivimos una desolación cultural terrible, donde los proyectos sociales y sus motores divinos y humanos languidecen, y seguimos inmóviles, sin entrar de lleno, como sociedad autónoma, en el debate tanto de la desarticulación occidental como en el de saber quiénes somos. 